\title{
FEMORAL NERVE INJURY FROM ABDOMINAL RETRACTORS
}

\author{
F. G. Ruston, M.D., and V. L. Politr, M.D. ${ }^{1}$
}

IT is oвvious from the title that this paper should be directed to a surgical group instead of to the "Sleeping Partners," as anaesthetists have been so aptly labelled by Punch (1). However, the etology of nerve lesions is important to the anaesthetist, especially if spinal, epidural, or some other form of conduction anaesthesia has been used. The following examples of femoral nerve injury by abdominal retractors are presented to illustrate this point.

\section{Case Presentations}

\section{Case 1}

A female patient, age 28 years, was admitted to the Hamilion General Hospital on August 15, 1954, for an abdommal hysterectomy to terminate a three and one-half months' pregnancy. The medical consultants advised this as the patient was experiencing increasing respiratory distress and morning sickness. These symptoms had started three weeks prior to admission and were characterized by fatigue, shortness of breath, nonJroductive cough, and wheezing in her chest. She had not been troubled like this in Ler Jrevious pregnancies.

T.e Jast history is important, for she had pleurisy with effusion in 1942 and was hospitalized in a western sanatorium. In 1944 she had an elght-rib thoracoplasty to collapse a tuberculous cavity. In 1945 she was discharged from the sanatorium and, following this, she had three viable pregnancies. She was hospitalized again for pneumonia in 1950. The last pregnancy was complicated by pyelitıs, and finally in 1953, she had a nervous breakdown.

On examination the evening before operation it was noted that the patient was quite apprehensive. The moral issue of terminating the pregnancy was troubling her. She was a thin woman, showing some dyspnoea without cyanosis, and coughing occasionally. There was a residual deformity of the left chest from the thoracoplasty. Râles and rhonchi were present throughout the whole chest. The blood pressure and heart were normal. Laboratory reports were negative except for the haemoglobin, which was 62 per cent.

The patient wished to have a spinal anaesthetic since as a result of her previous anaesthetics she had developed a fear of losing consciousness.

On August 19, 1954, the patient received a preoserative sedation of Seconal ${ }^{\circledR}$ gr.iss, morphine sulphate gr. $1 / 6$, and hyoscine gr. $1 / 150$. She was normally sedated, cooperative, and reminded me of my promise not to put her to sleep. She recerved a spinal anaesthetic, the tap being made between lumbar interspaces 3 and 4 , and $12 \mathrm{mg}$. of Pontocaine ${ }^{\circledR}$ with 10 per cent dextrose were injected. Anaesthesia and relaxation were good and no supplement was required, although me seridine $25 \mathrm{mg}$. was given intravenously to further sedate the patient, as she was talkative. She was content and did not have any discomfort during the spinal tap or the operation.

The surgical approach was through a low transverse incision in which the recti muscles were not divided. A Mann se f-retaining retractor ${ }^{2}$ was used with the two fixed lateral blades in the usual position for pelvic laparotomies. The hysterectomy was performed without difficulty and without excessive bleeding, although a transfusion of

${ }^{1}$ Hamilton General Hospital, Hamilton, Ontario.

2The Mann self-retaining retractor was designed by Dr John Mann, Toronto, and is manufactured by Imperial Surgical Company, Toronto, Ontario. 
$500 \mathrm{cc}$. of matched blood was administered during the operation. There was no bleeding present at the time of wound closure.

An additional $500 \mathrm{cc}$. of blood was given to the patient postoperatively. She comJlained of abdominal pain which meperidine $100 \mathrm{mg}$. would not control. However, Jromoran $2 \mathrm{mg}$. proved effective. Two days later, the patient complained o numbness and weakness in her left leg. This was more marked on the third postopera ive day and was accompanied by abdominal distention, pallor, and dyspnoea. A Levine tube was inserted mto the stomach and continuous gastric suction was started. The haemoglobin fell to 48 per cent and she was transfused again. The surgeon called a neurosurgeon in consultation. Here are excerpts from his report. "The day before I saw her, she found that she could not extend her left leg at the knee. At the same time she was distended and had an ileus. It is my opinion that a certain amount of haemorrhage had occurred in the retroperitoneal space. In my opinion. the weakness of the leg is due to the blood clot causing pressure on the lumbar roots going to make up the femoral nerve. It is quite easy to imagine a blood clot pressing on these roots beneath the peritoneum over the psoas muscle. On this examination of August 22nd, there was a patch of analgesia in the lower L3 dermatome and hyperaesthesia on part of L4 dermatome. She could not extend her leg at the knee, although the quadriceps did contract slightly on the lateral side. The le $t$ knee jerk was almost gone. On August 25th, the leg could be extended weakly and t 2 sensory loss was less. In my opinion, this incident was merely a complication of the operation which will be corrected when the blood clot has been absorbed. I do not see how the spinal anaesthesia could be implicated. I think she will make a good recovery in a few weeks' time."

There was a gradual decrease in numbness and an increase in quadraceps power following a course of physiother:apy. She had completely recovered from neurological symptoms at the end of five months.

\section{Case 2}

A female patient, age 33 years, had been observed for some time because she had symptoms of Jelvic disease which were clouded by a marked emotional background. After an additonal gynaecological consultation, it was decided to hospitalize her and do a diagnostic curettage and a polvic laparotomy. The patient was subjected to these procedures on October 29, 1955, under combined spinal and thiopentone anaesthesia. The spinal tap was difficult and, on the first attempt, the patient experienced a stabbing pain down her right leg. The spinal needle was reinserted and good anaesthesia resulted from the injection of Pontocaine and dextrose. Following the curettage, a left paramedian incision was made and a Mann retractor was put in place in the usual manner. The patient was placed in a very steep Trendelenburg position in which the thighs were hyperextended and a presacral neurectomy, bilateral ovarian neurectomy, and removal of a papilloma from the right ovary were done. The abdomen was closed after numerous plaques of endometrosis had been cauterized. As soon as the patient had recovered from her anaesthetic, she complained of numbness and weakness in her left reg. This persisted and she was examined by an internist ten days later on November 9 . Here is a quotation from his report. "Noticed inability to move left leg from the knee down after regaining consciousness. The leg felt like a log and numb. Numbness 1 vas on inner side of thigh and calf and', is gradually disappearing and she is aware of tingling with the return of power. On examination, there is a-reduced touch sensation -she can feel but cannot differentiate over the inner side of thigh and calf. Pain sensationsharpness is reduced over this area. Vibration sense is O.K. The right knee and both ankle jerks are very active, but the left knee jerk is markedly reduced. Extension of knee and flexion of ankle is greatl reduced. Muscles tighten verg markedly but movement doesn't occur against the slightest resistence. I suggest some nerve damage but a large functional overlay is present."

A note made on November 18, nearly three weeks after operation, stated that "Flexion of the ankle is practically normal but extension of the knee is still poor. Can differentiate 
sensation and reflexes are normal. She gets up by herself but tends to drag her left foot after the first few steps."

She was examined by a surgical consultant on November 20. "There is a diminished sensation on the medial side of the thigh and calf and somewhat reduced left knee jerk-some weakness of left quadraceps and adductors. I believe that this represents stretching or contusion of the femoral-obturator nerve and this will almost oertainly recover. Suggest no other treatment than her present physiotherapy and encouragement."

She was discharged to her home on December 10, having been in hospital ten weeks. Progress notes from her record after she had left the hospital are as follows. "Muscle ;ower in left leg considerably improved but there is still some weakness." There was no urther mention of the leg when she was examined on April 13, 1956. She was reexamined on several occasions regarding endometrosis, the last time being August 19, 1957 , and there was no further reference to her leg.

Case 3

A woman, age 38 years, was admitted on March 13, 1955, with the complaint of dysmenorrhoea of increasing severity during the past year, especially at the beginning, of the menstrual period, low back pain, and, more recently, of stress incontinence. Phys_cal examination was essentially negative, exce t for the findings of vaginal examination. Blood pressure was 130/80, haemoglobin, 30 per cent, white blood count, 9,600, and W. R., negative.

On March 15 she came to surgery and, after an examination under anaesthesia, it was decided that a hysterectomy should be done by the abdominal approach. Anaesthesia was induced with $300 \mathrm{mg}$. of thiopentone and maintained with cyclopropane and oxygen in closed system. The necessary relaxation was obtained with Tubarine ${ }^{\circledR} 9 \mathrm{mg}$. The length of anaesthesia was 1 hour and 50 minutes. She received $500 \mathrm{cc}$. of 5 per cent dextrose in distilled water during and following the operation. Pulse and blood pressure remained steady in the region of 72 and $110 \mathrm{~mm}$. of mercury, respectively. She arrived in the recovery room in good condition and returned to the ward in a short time.

The gynaecologist described the approach as "a transverse muscle cutting incision" The Mann abdominal retractor was inserted in the conventional position. The operation was a total hysterectomy with left salpingo-oopherectomy and appendectomy. At 3.30 P.M. she was transfused with $500 \mathrm{cc}$. of cross-matched blood along with additional fluids. She developed abdominal distention and this was treated with Prostigmine and fluids.

On March 18, two days after ojeration, she complained about her legs being panful. The following day she had numbness in her right leg and diminished feeling in her left. One week later her leg collapsed when she got out of bed and she fell on the floor. On March 26 she complained of increasing discomfort in her legs. For the next four weeks she continued to have difficulty in moving about the ward. She had to be assısted in walking. She walked as though on tip-toes. During this time there were numerous reports of falling while walking.

She was examined by one of the staff surgeons, but no record was made of his findings except that she should be placed on anticoagulants and, later, Jhysiotherapy. She was seen by the anaesthetist the day following the operation and was ound to have recovered from the anaesthesia. She was not seen again until the gynaecologist reported that the anaesthetist had caused a "paraplegia with your spinal anaesthetic." She was examined superficially regarding the muscular weakness in her legs. Her chief difficulty was that she could not keep her legs straight or raise them from the bed. Extension of the knees could not be carried out well though she could dig her heels strongly into the mattress.

She remained on ?hysiotherapy for some time and was finally discharged from hospital on May 7,1555 , after a stay of six weeks. She continued to have difficulty in walking for several months but has since fully recovered the use of her legs.

A d-scussion of the case with the individuals concerned gave a diagnosis of bilateral femoral nerve paralysis due to trauma. It is regretted that a "ull neurological examination of the lower extremities had not been recorded on the corisultation report. 


\section{Discussion}

A review of the literature on femoral nerve injuries over the past five years is surprisingly meager. However, there is one recent article, "Nerve Injuries Incident to Anesthesia and Operation," by Nicholson and Eversole (2), which, while it covers other peripheral nerves, only. refers to the femoral or anterior crural nerves in a table, "Incidence of Peripheral Nerve Injuries," which lists figures from a text dated 1933 (3). In this table there were 19 femoral nerve injuries out of a total of 729 peripheral nerve injuries from all forms of trauma. In a modern text, Neurosurgery in General Practice (4), even injuries of the peripheral nerves of the lower extremities are covered by one sentence, "Lesions of these nerves are relatively rare in civil practice and they will not, therefore, be discussed here." So it may be assumed that reports of femoral nerve injuries are comparatively rare in rnedical literature. Perhaps the reason that injury is not more frequent is that care is used by the surgeons because of the proximity of the iliac vessels. However, the femoral nerve is vulnerable to direct pressure and stretching because of the exposed relationship to the psoas muscle in the portion proximal to the femoral canal.

Figure 1 shows the schernatic distribution of the femoral nerve. Figure 2 plots the dermatomes supplied by this nerve. It is evident that these figures are applicable to the pattern of involvement of the three cases mentioned'above.

There was a rather reasonable, yet quite understandable inference drawn from the complications in these patients. Each was originally thought to have been a complication of spinal anaesthesia. The first was initially believed by the surgeon to be a cauda equina syndrome. The anaesthetist also had some misgivings until the etiology became evident. It seemed that the picture was one of direct pressure on, or stretching of, the femoral nerve. An extraperitoneal haemorrhage also developed after the removal of the retractor, because there was no evidence of bleeding or haematoma prior to closure of the incision. Examination of the Mann retractor (Fig. 3) shows that the two lateral fixed blades have sharp edges (Fig. 4) which would impinge on the femoral nerves in the low transverse incision. An example of this is seen in Figure 5. This was discussed with the gynaecologist and the neurosurgeon and they agreed that this explanation was reasonable.

In case 2 the patient believed that her numbness and weakness resulted from the initial spinal tap. She had complained of a shooting pain down her right leg, whereas the left leg was the affected one. A paramedian incision was made and a steep Trendelenburg position with hyperextension of the thighs was used. Figure 6 shows the lateral blades resting on the psoas muscle in the area of the femoral nerve. It must be pointed out that the head of the table was only slightly tilted for this photograph.

Case 3 developed bilateral femoral nerve involvement. The surgeon greeted the anaesthetist with "Well, it's happened again, paraplegia with your spinal anaeșthetic." This time the answer was "Why, I gave her a general anaesthetic"!

Fortunately, all these patients have fully recovered. Moreover, there is no doubt in the minds of the surgeons and the anaesthetists that the cause of 
the femoral nerve trauma was pressure exerted by the Mann retractor when it was inserted in the usual manner for pelvic laparotomies. Doctor Mann stated, at an informal discussion, that the retractor was not designed for the low transverse or Pfannenstiel's incision. Doctor R. T. Weaver (5) emphasizes that the

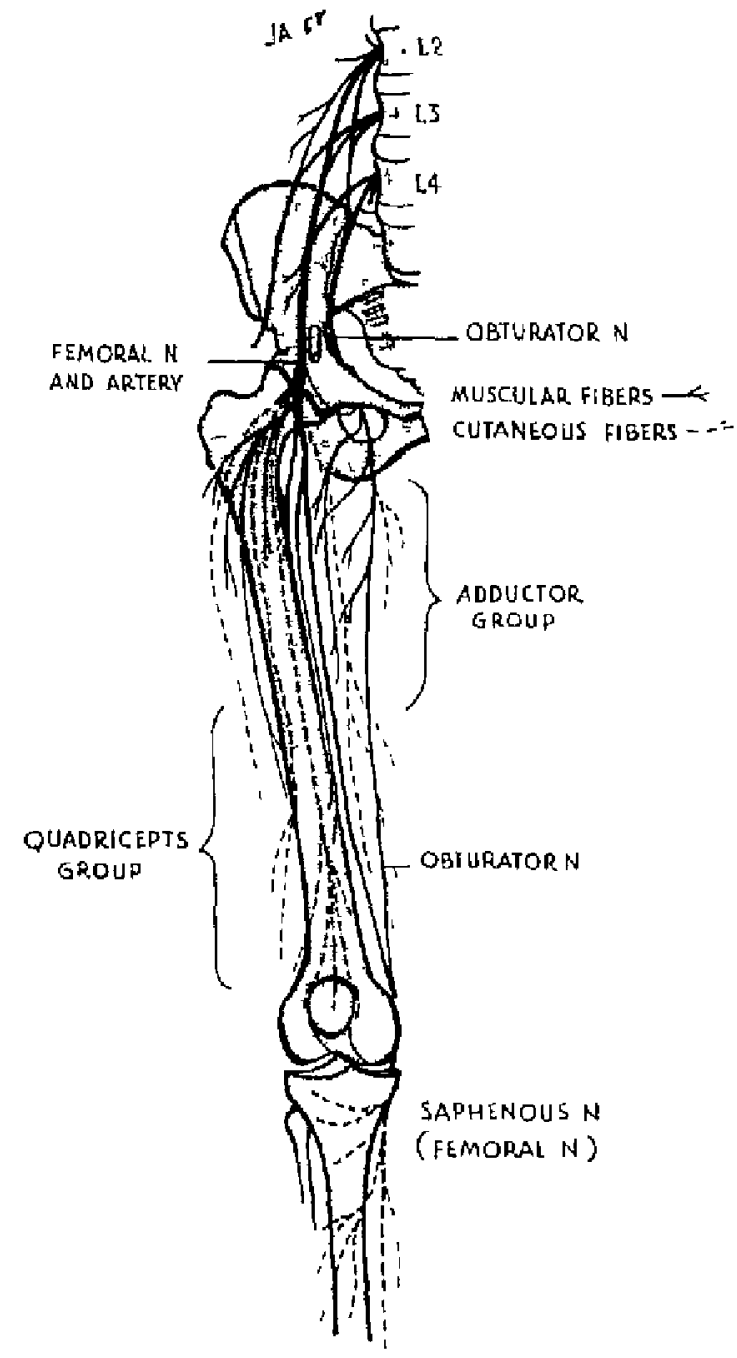

Fucure l. Schematic distribution of femoral nerve

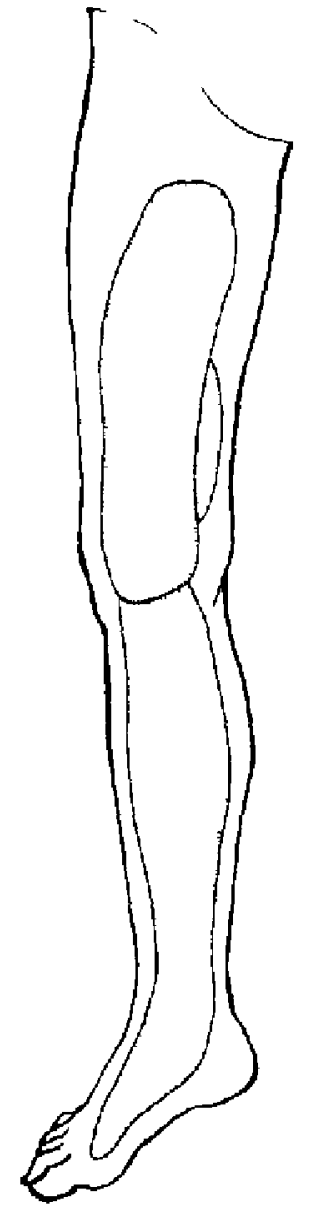

Frgune 2 Lumbar 3 and 4 dermatomes supplied va femoral nerve

Mann retractor should be used in the reversed positon for pelvic laparotomies in either the vertical or the low transverse incisions so that the lateral blades do not press on the femoral nerves or the iliac vessels. Moreover, he releases the ratchet momentarily during the operation so that no unduly prolonged pressure will be placed on the incision. In his opinion, the Mann retractor offers maximal harmless exposure if these precautions are practised. Figure 7 shows the safe position for the low transverse incision; the point of the forceps is over the femoral nerve and the retractor blade is lateral to this. Figure 8 demonstrates the safe position for the vertical approach. 


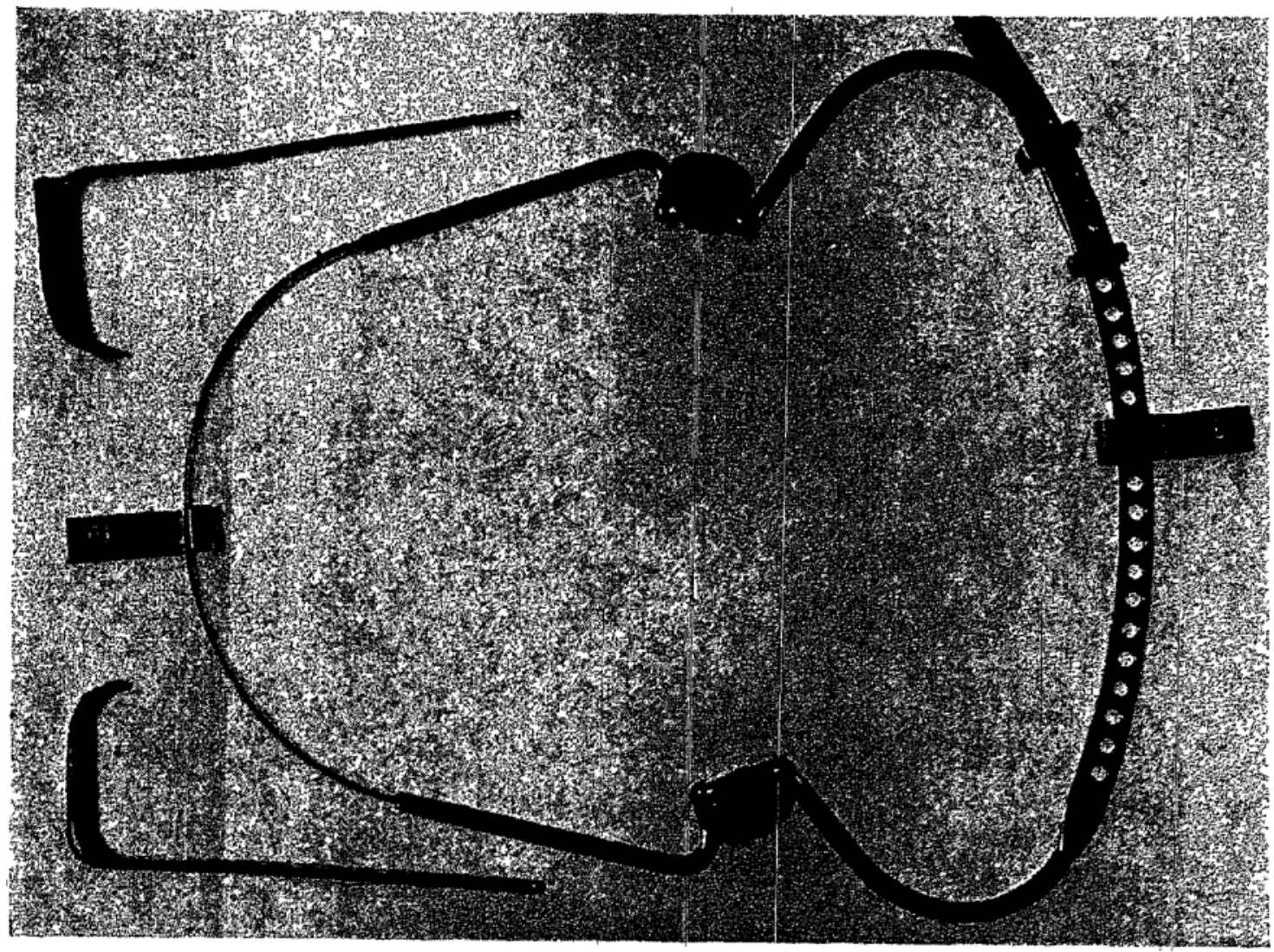

FIGURE 3. Mann selt-retaining retractor.

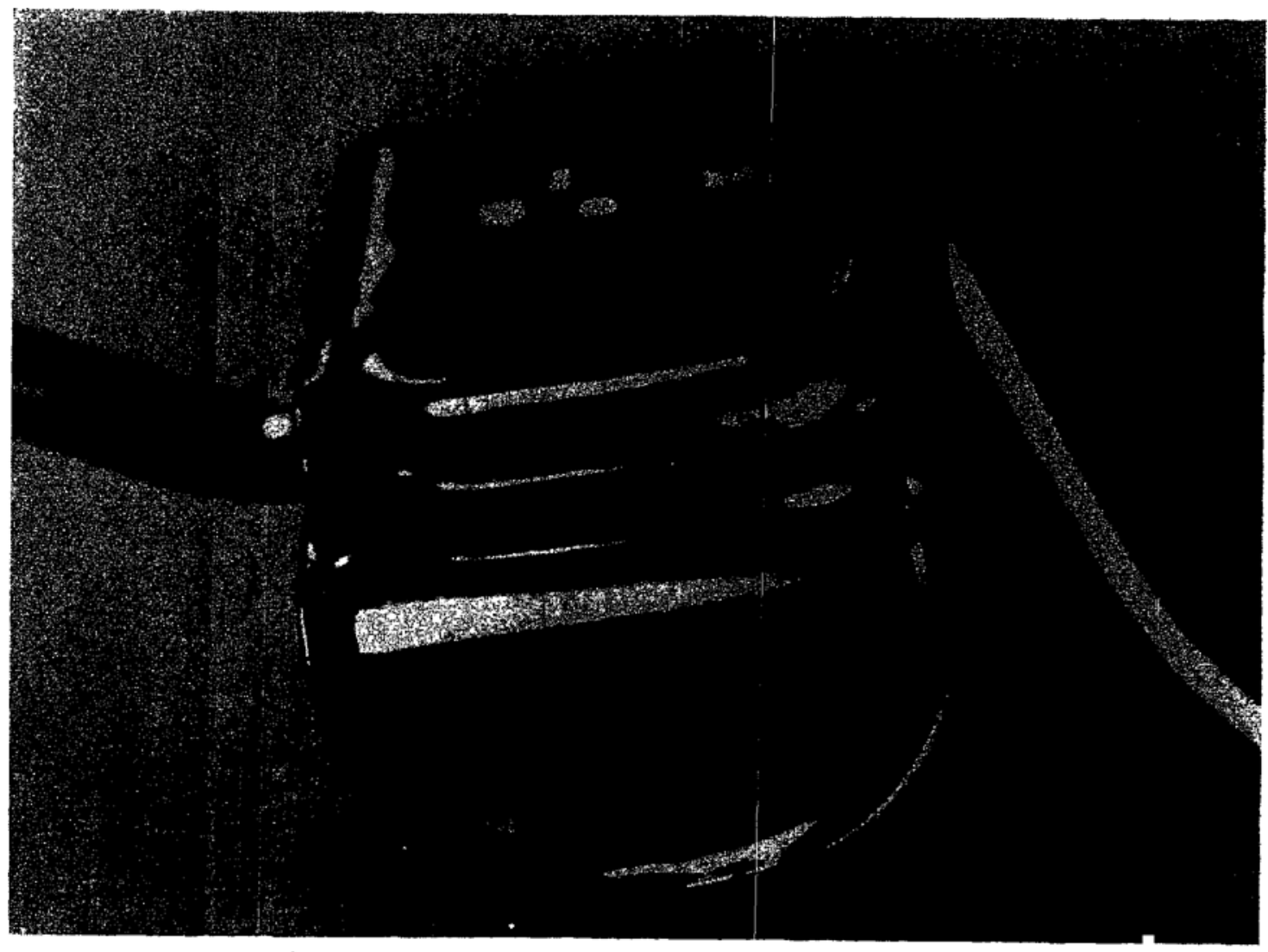

Ficure 4. Fixed lateral blade of retractor showing the rolled sharp margin. 


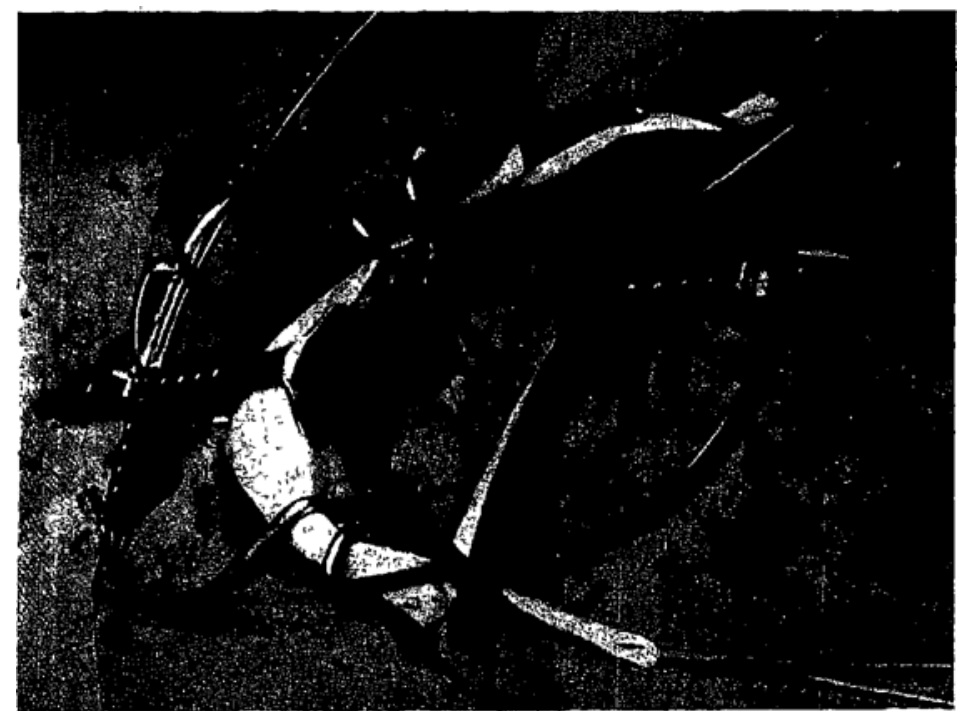

Ficure 5 Conventional position of retractor in low transverse incisions-large blade on pubes

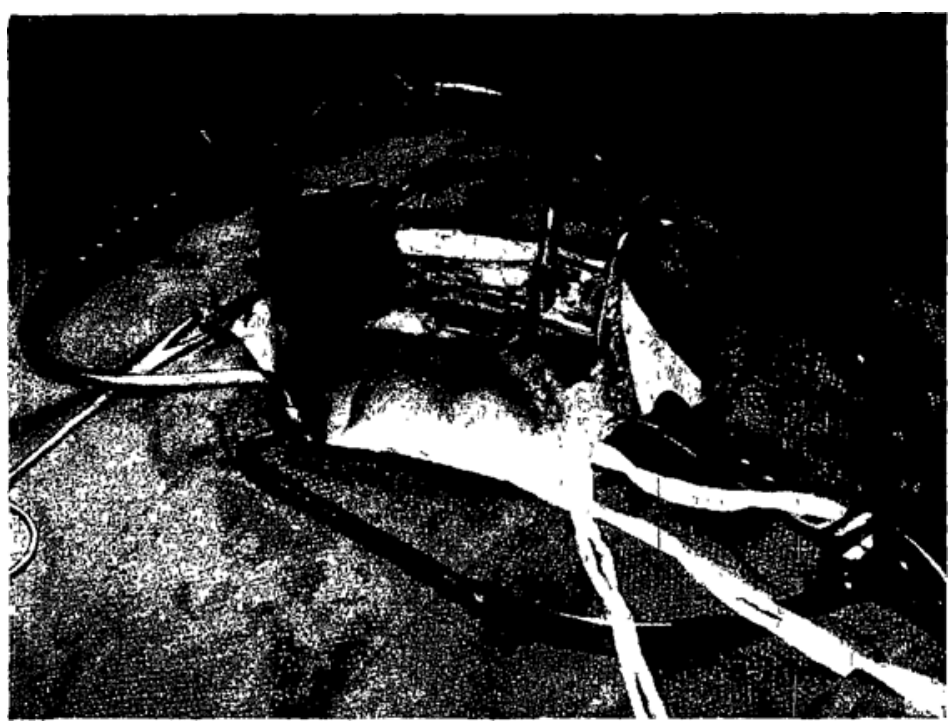

Figure $\boldsymbol{\theta}$ Mann retractor in conventional position for vertical incision 


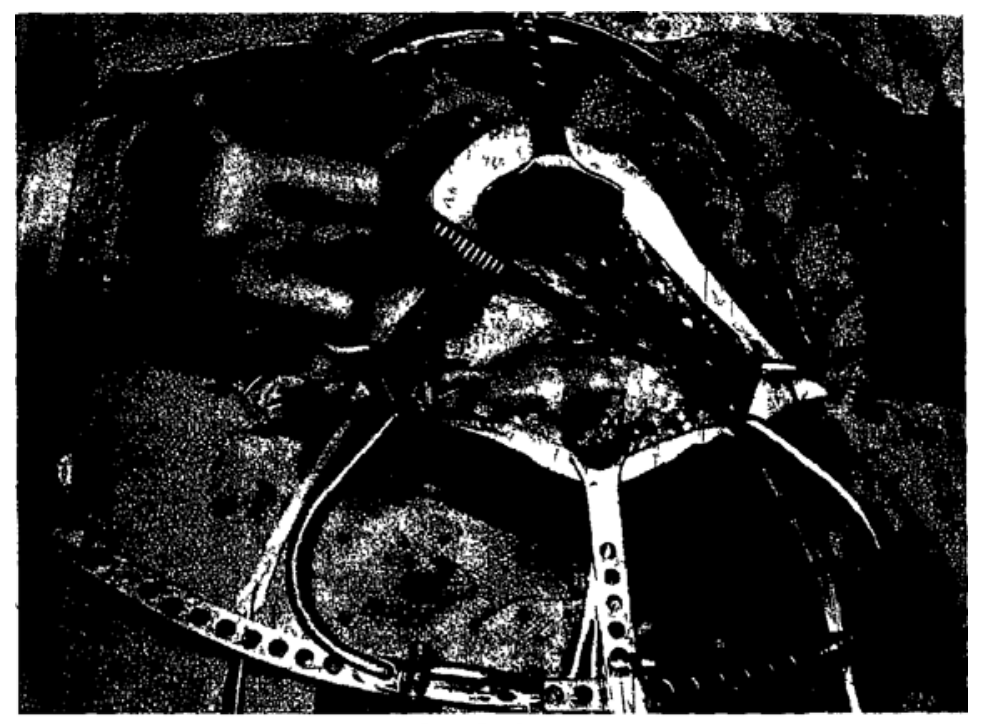

Figune 7 Retractor reversed-large blade on pubes-low transverse incision

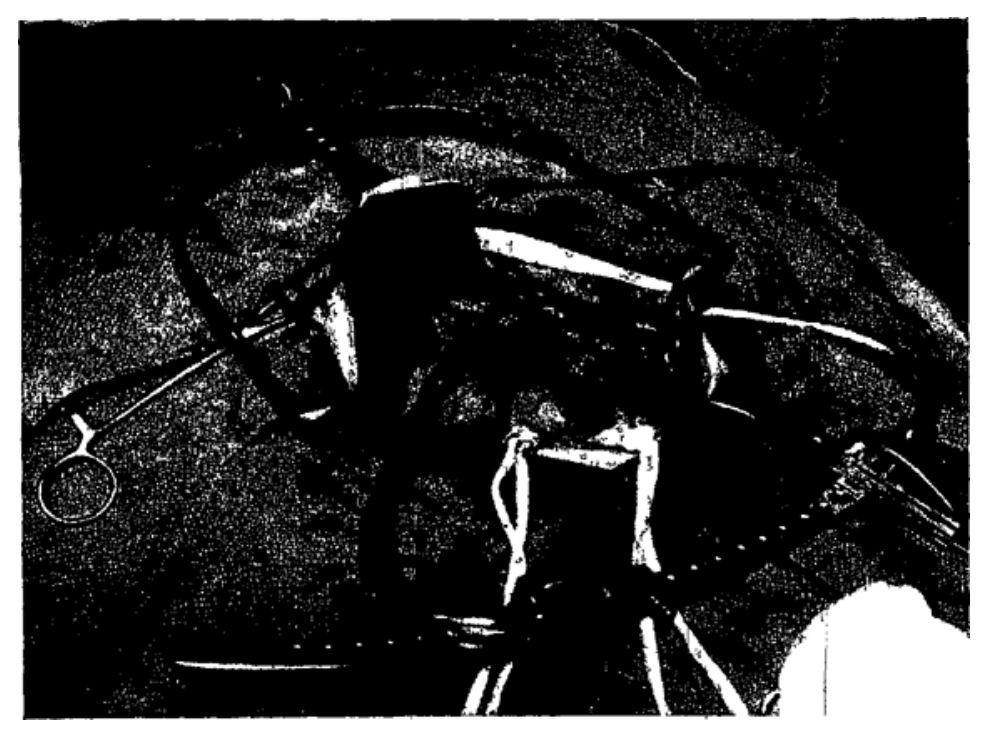

Figure 8 Safe postion of retractor for vertical incision 
It is significant that one of the gynaecologists has abandoned the use of this retractor because of the neurological complication which was sustained by his patient. It is also interesting that there has been no recurrence of femoral nerve trauma in the Hamilton hospitals since 1955 when the danger of the usual position was recognized and the modifications suggested by Doctor Weaver were put into practice.

\section{SUMMARY}

Three patients who had pelvic laparotomies have been presented. These showed transient femoral nerve involvement following the use of the Mann abdominal retractor. Two patients who recaived spinal anaesthetics developed unilateral and one who had a general anaestıetic developed a bilateral paralysis. No further cases have occurred since 1955 when the danger from the pressure of the lateral blades in the conventional position was recognized, and the retractor was placed in a reversed position.

\section{ACKNOWLEDGMENTS}

Appreciation is due to Doctors M. S. Ellenzweig, L. E. Lotimer, and H. R. Morgan for permission to report clinical material, and to Miss J. Ashley, photographer and illustrator of the Hamilton General Hospital, for the illustrations.

\section{RÉSUMÉ}

Les auteurs présentent l'histoire des cas de trols malades qui ont présenté, au cours des années 1954 et 1955, des séquelles transitoires à la suite de blessure du nerf fémoral. La première malade a subi une hystérectomie. Elle a présenté de l'engourdissement et de la faiblesse du quadriceps gauche, signature d'une lésion du nerf fémoral, à la suite d'une anesthésie rachidienne et de l'emploi d'un écarteur abdominal Mann dans une incision transversale basse où les muscles droits n’avaient pas été divisés.

La deuxième malade a présenté un tableau semblable à celuı de la première malade à la suite d'une laparatomie basse au cours de laquelle on a pratiqué une résectıon du présacré et on a cautérısé des plaques d'endométriose. On avait pratiqué une rachianesthésie et on s'était servi d'un écarteur de Mann de façon conventionnelle pour une incısion paramédiane. La troisième malade, à la suite d'une hystérectomie sous anesthésie générale, a présenté une paralysie bilatérale du nerf fémoral. L'incision était du type trans-transverse basse.

Au début, chacun croyait que ces malheureuses présentaient des complications post-rachidiennes, même celle qui avait reçu une anesthésie générale. On a noté, toutefois, qu'en mettant en place l'écarteur de. Mann dans la position habituelle pour les laparatomies, il y avait un risque que les ailes latérales fixes pointues ne compriment le muscle psoas dans la région du nerf fémoral et des vaisseaux iliaques. Le fait qu'un gynécologue ait abandonné l'usage de cet écarteur depuis qu'une de ses patientes a subi des blessures devient éloquent. Bien plus, dans les 
RUSTON \& POLITI. FEMIORAL NERYÉ INJURY

hôpitaux de Hamilton, depuis que le docteur R. T. Weaver a suggéré d'em sloyer l'écarteur de Mann de façon à ce que les ailes latérales portent à un endro $t$ plus élevé et ne compriment pas les muscles psoas dans une région dangereuse pour le nerf fémoral, l'incidence de cette complication est complètement disparue.

\section{REFERENCES}

1. Gordon, Richard. Sleeping Partner. Punch, Oct. 7, 195.3

2 Nicholson, M. J \& Eversole, U. H. Nerve Injuries Incident to Anesthesia and Operation. Anesth. \& Analg. 36. 19-36 (July-August, 1957).

3. Pollock, L. J., \& Davis, L. E. P'enpheral Nerve Injuries, pp. 678. New York Paul B. Hoeber, Inc. (1933).

4. Ver Brugghen, A. Neurosurgery in General Practice, pp. 150. Springfield, Ill. Charles C. Thomas (1952).

5. Weaver, R. T. Personal communication. 